fields in order to diminish their evaporation. Attempts have been made in several countries to reduce the natural evaporation from lakes and reservoirs by spreading and maintaining a suitable chemical film over the water surface.

The third annual report on Weather Modification of the U.S. National Science Foundation shows that these problems are much in mind at the present time. It seems, however, from the existing results that progress will be slow. The next few years will see a consolidation of facts and basic ideas on the mechanism of the physical meteorological and climatological processes which govern the behaviour of our atmosphere, rather than any spectacular advance in man's attempts to modify the weather to any marked degree. Small local phenomena may indeed be brought into being, dissipated or modified. For the time being, meteorologists should not allow their imagination to run wild with the hope of changing things effectively on a wide scale. A. H. Gordon

\title{
THE LOW TEMPERATURE RESEARCH STATION, CAMBRIDGE
}

$\mathrm{T}$ HE first International Congress of Food Science and Technology held in London during Septem. ber directed attention to the ever-increasing interest in the nature of food materials and modern techniques of food production. The recent publication of the annual report for $1961 *$ of the Low Temperature Research Station, Cambridge, is therefore timely and will, no doubt, be received with particular interest by those who visited the Research Station during the week of the Congress and attended sessions which dealt with papers on the progress of its activitios.

An account of some of these activities, set against a background of the present state of each subject, forms the essential content of the report. Together with its accompanying brochure, The Low Temperature Research Station, Cambridge $\dagger$, the wide range of interests of the Station is well presented. A particularly noteworthy aspect is the substantial contribution to modern food handling and processing practices emerging from the results of its research work.

The preface describes the function of the Station as research into the principles of the preservation of foods. As would therefore be expected, considerable attention is directed to the newer methods of food preservation, such as radiation sterilization and freeze dehydration.

"Accelerated Freeze Drying of Meat" is the title of the second report, dealing with ultimate $p H$ on the quality of freeze-dried meat. The results obtained should be of particular interest to those concerned with potential applications of accelerated freeze drying to the preservation of meat. This report is preceded by a detailed survey entitled "Anatomy and Physiology in Meat Research". Factors influencing quality are summarized under the headings of "Constitution" and "Condition".

The data presontod on immersion freezing (air and liquid) of poultry are of immediate practical interest. A roassessment of heat extracted in freezing chicken should be found useful in equipment design. It will be of advantage to have further data with the publication of full experimental details.

Much of the pioneer work on liquid whole egg pasteurization was earried out by the late Dr. J. Brooks. This has now lod to the successful develop. ment of the amylase test. The effectiveness of the test ean be judgod from the last paragraph of this account: "The results of a number of technical trials recently carried out indicated that the amylase test

*Agricultural Research Station. Low Temperature Research Station, Cambridge. Annual Report, 1961. Pp. 40. (London: H.M. Stationery Office, 1962.) $2 s$. 6d. net.

$\dagger$ University of Cambridge and Agricultural Research Council. The Low Temperature Research Station, Cambridge. Pp. $48+3$ plates. (London: H.M. Stationery Office, 1982.) 28. 6d. net. could be used to detect an error of $0.5^{\circ} \mathrm{F}\left(1^{\circ} \mathrm{C}\right)$ in the setting of the temperature control instrument of a commercial pasteurizer; serial results could be made available $1 \mathrm{~h}$ after taking the first sample. The amylase test has also been applied to samples of pasteurized whole egg of widely different origin and has correctly indicated the severity of the heating treatments used".

Under the title "Twelve Years of Radiation Preservation Research" progress in another branch of food research is briefly reviewed. Much interest has been shown to exist in this new method of food preservation and some of the results reportod here show considerable promise. The study of radiation pasteurization of frozen whole egg carried out in collaboration with the Isotope Research Division of the Atomic Energy Research Establishment was reported at the Congress. This may prove to be of commercial value. The effects of irradiation of other foods, including pork sausage and fish, are also mentioned. The latter application deals with white fish species which have been found to respond well to treatment and, at the maximum tolerable dose, considerably extended the storage life at $0^{\circ} \mathrm{C}$ and $4^{\circ} \mathrm{C}$.

The successful application of all methods of food preservation so far discussed depends on adequate packaging. Gas sampling in vacuum packs forms the main topic in the report entitled "Physical Problems in Packaging of Foodstuffs". Gas analysis is of great importance in assessing this type of package performance and a systematic study of the subject should be welcome.

The technique of gas chromatography has also been applied to the analysis of flavour. Work recently started on the flavour of meat and poultry and preliminary results indicate that here, too, the breakdown products of amino-acids can make a notable contribution to flavour. The study of flavour during irradiation should yield further results of considerable interest.

Two other reports, dealing with phospholipids and the elassification of micro-organisms, complete a review of some of tho activities during 1961.

The report contains a comprehensive list of recent publications. In addition, references to the literature are quoted at the end of most of the reports presented. A photograph depicting one of the rooms at the Meat Research Laboratory, Cherry Hinton, is included.

Other photographs appear in the accompanying brochure together with selected excerpts from the annual reports 1959-62. This booklet also includes an account of the work and achievements of Sir William B. Hardy, founder of the Low Temperature Research Station.
R. A. P. Wertherm 